\title{
Breast Imaging Chameleon: Pseudoangiomatous Stromal Hyperplasia Presenting as Breast Malignancy
}

\author{
Rabail Raza ${ }^{1}$, Kulsoom Fatima ${ }^{1}$, Muhammad Usman Tariq ${ }^{2}$ \\ 1. Radiology, Aga Khan University Hospital, Karachi, PAK 2. Pathology, Aga Khan University Hospital, Karachi, PAK
}

Corresponding author: Kulsoom Fatima, kulsoom.fatima@aku.edu

\begin{abstract}
Pseudoangiomatous stromal hyperplasia (PASH) is a benign mesenchymal proliferative lesion of the breast, often an incidental finding on breast biopsy specimens and rarely presents as a palpable lump. The case being reported is interesting as a lactating female presented with gross left breast enlargement due to a huge firm mass with skin thickening and palpable left axillary lymph nodes. A provisional diagnosis of left breast malignancy was made and the patient extensively worked up with ultrasound, CT scan, bone scan and core biopsy. The histopathology, however, revealed PASH of the breast. There was no invasive or in situ malignancy. The patient was successfully managed conservatively.
\end{abstract}

Categories: Obstetrics/Gynecology, Pathology, Radiology

Keywords: palpable lump, breast, ultrasound, malignancy, pseudoangiomatous stromal hyperplasia, benign

\section{Introduction}

Pseudoangiomatous stromal hyperplasia (PASH) of the breast, as the name suggests, is a benign process which on histology typically consists of anastomosing slit-like spaces within a background of dense fibrous stroma [1]. It is a usually a coexistent finding on histological examination of breast biopsy specimens and presentation as a palpable lump is rare. Since the first case reported in 1986 by Vuitch et al., approximately 150 cases of tumorous PASH have been reported in the literature [1,2]. The etiology of PASH is not clearly elucidated, but according to most investigators it represents a proliferative response of myofibroblasts under the influence of hormonal stimuli [3]. It, therefore, most commonly presents in premenopausal or perimenopausal women and may also be encountered in postmenopausal women receiving hormone replacement therapy [4]. Tumorous PASH presents as a slow-growing mass, with an average size of less than $7 \mathrm{~cm}$ and the clinical and radiologic features often suggest an alternate more common diagnoses, such as fibroadenoma, phyllodes tumor or hamartoma requiring histopathological confirmation [5,6]. As association with malignancy or malignant transformation is very rare, smaller incidental lesions may be periodically imaged to assess interval growth while surgical excision is reserved for larger symptomatic lesions [6].

Received 05/11/2020

Review began 05/20/2020 Review ended 05/21/2020 Published 05/30/2020

(c) Copyright 2020 Raza et al. This is an open access article distributed under the terms of the Creative Commons Attribution License CC-BY 4.0., which permits unrestricted use, distribution, and reproduction in any medium, provided the original author and source are credited.

\section{Case Presentation}

A 30-year-old lactating female presented to the breast surgery clinic with a complaint of left breast heaviness and gradual enlargement since one year. Physical examination revealed gross asymmetric left breast enlargement with an ill-defined palpable lump measuring approximately $12 \times 4.6 \mathrm{~cm}$. There was overlying skin thickening with induration, although no redness and a palpable left axillary lymph node. As the patient was lactating, she initially underwent bilateral breast ultrasound, which showed a large circumscribed mass, wider than tall without any posterior acoustic shadowing predominantly in upper outer quadrant of the left breast with few intralesional cystic spaces showing mild vascularity on color Doppler and an abnormal left axillary lymph node (Figure 1). 


\section{Cureus}

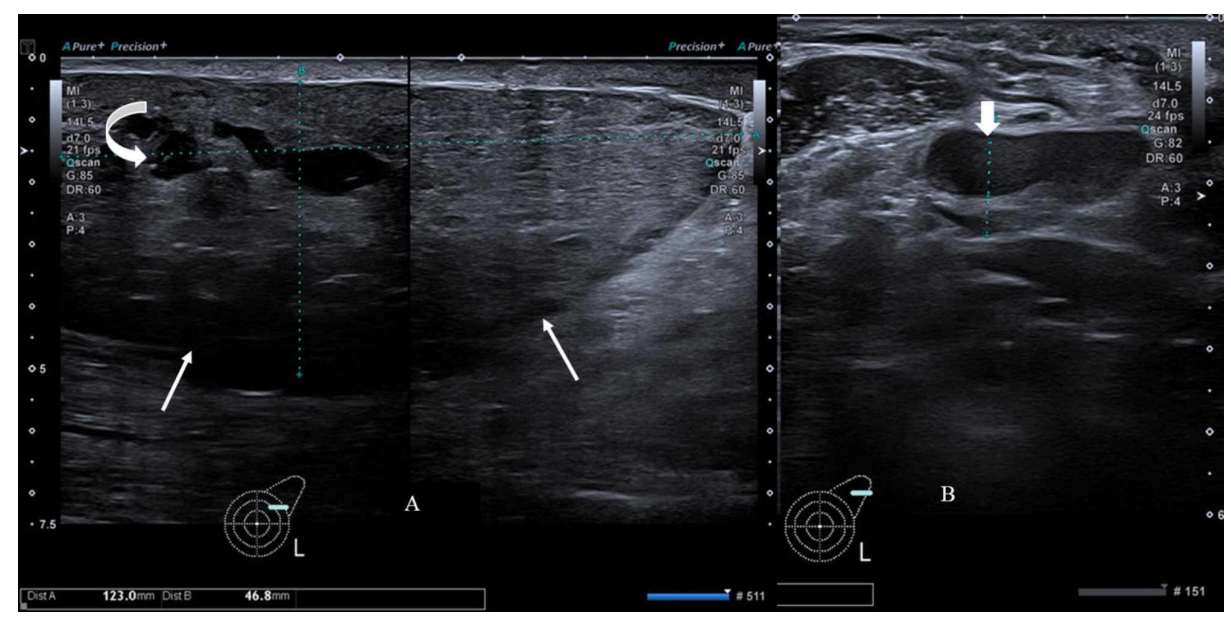

\section{FIGURE 1: Gray scale ultrasound image of left breast and axilla}

(A) Image shows a solid, circumscribed mass (thin white arrows) predominantly in upper outer quadrant of left breast with few cystic spaces (curved arrow). (B) Image shows abnormal left axillary lymph node with asymmetric cortical thickening (short thick arrow) and displaced hilum.

The short axis of the lymph node measured $12 \mathrm{~mm}$ and the cortical thickness $8 \mathrm{~mm}$ with compressed fatty hilum. A breast imaging-reporting and data system (BI-RADS) category 4 assessment was given, and biopsy of the lesion and the axillary lymph node was recommended.

The patient was electively admitted for ultrasound-guided core biopsy, blood workup, CT chest, abdomen and pelvis scan, and bone scintigraphy for metastatic disease. Contrast-enhanced CT of the chest, abdomen and pelvis showed edematous left breast parenchyma with a large well-defined solid enhancing lesion associated with overlying skin thickening (Figure 2).

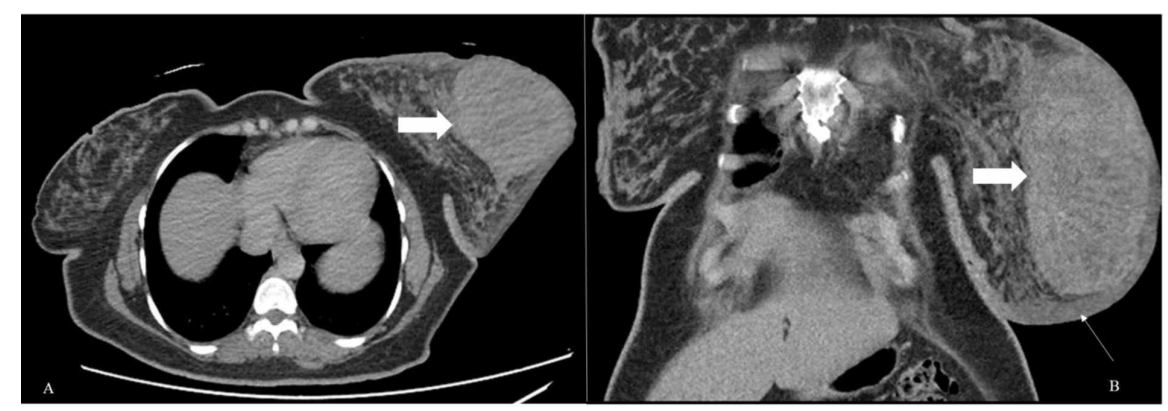

\section{FIGURE 2: Contrast-enhanced CT scan}

Axial (A) and coronal (B) images show large enhancing soft tissue mass in the left breast (thick white arrows). Marked skin thickening is also noted (long white arrow) as well as left breast edema.

Multiple enlarged left axillary lymph nodes were also noted associated with perinodal fuzziness. There was no visceral metastasis on CT scan. Whole-body skeletal scintigraphy was also negative for bony metastasis. On histopathology, the core specimen from left breast lesion revealed benign breast tissue exhibiting adenosis, stromal sclerosis and pseudovascular proliferation of mammary stroma delineated by endothelial cells without atypia, features representing PASH (Figure 3). 


\section{Cureus}

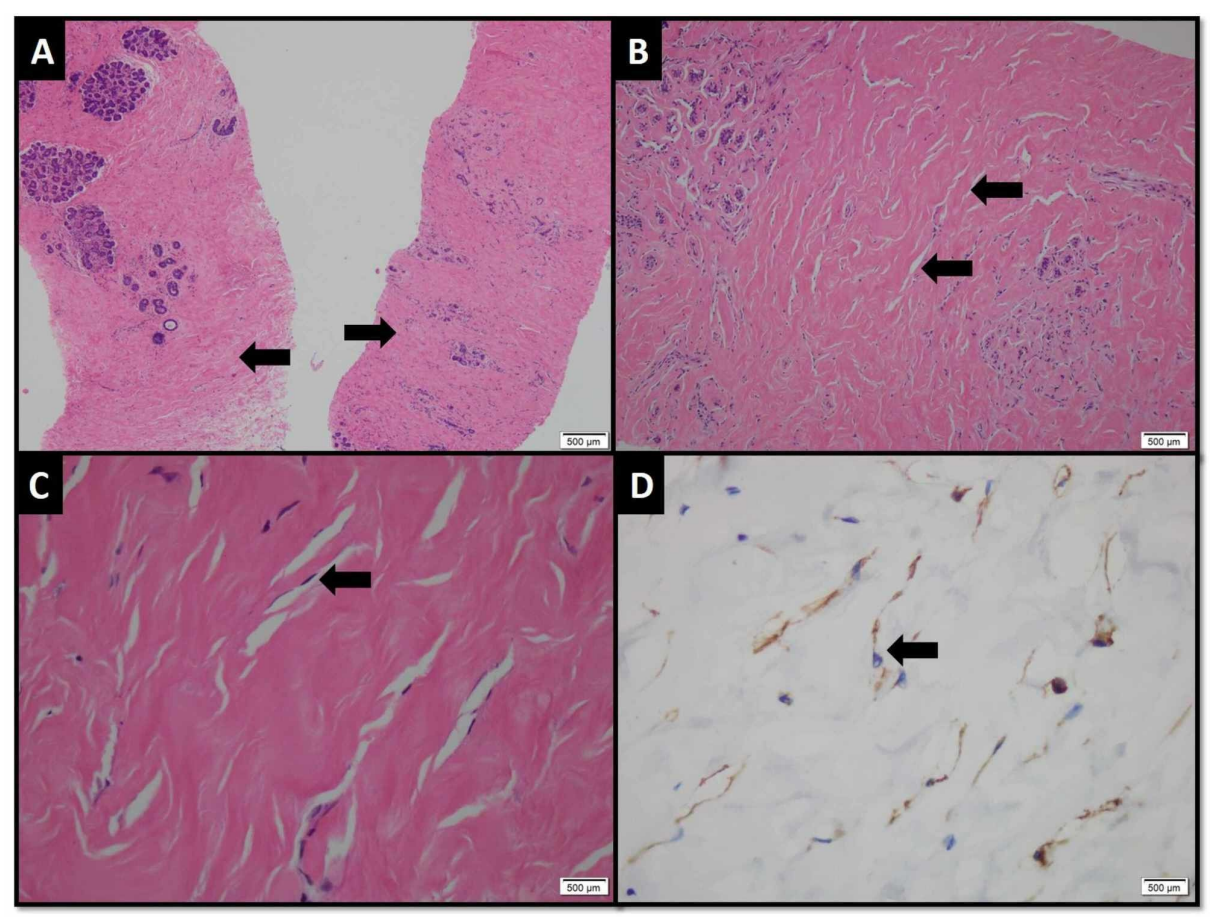

\section{FIGURE 3: Photomicrograph (H\&E and immunohistochemical stain)}

(A) Linear cores of benign breast tissue exhibiting ducts and lobule with surrounding hyalinized stroma (arrows. (B) Slit-like spaces mimicking thin blood vessels frequently seen in stroma (arrows). (C) These spaces are line by bland spindle shape cells (arrow). (D) The lining cells demonstrate positive expression for CD-34 immunohistochemical stain.

There was no evidence of ductal carcinoma in situ (DCIS) or malignancy. Core specimen from the left axillary lymph node showed benign lymphoid tissue exhibiting sinus histiocytosis and acute on chronic inflammation.

The patient received lactation suppression drug (bromocriptine) and anti-hormonal therapy comprising tamoxifen, and she showed significant clinical improvement.

\section{Discussion}

PASH is a benign entity characterized by a network of anastomosing slit-like spaces lined by spindle-shaped cells in a background of dense, collagenous proliferating breast stroma [2,3]. A proposed etiology is that this lesion is an abnormal response to progesterone and estrogen leading to myofibroblast proliferation; hence, it is more commonly seen in premenopausal or perimenopausal women and postmenopausal women on hormone replacement therapy $[4,7]$. PASH can be incidentally found in biopsy specimens performed for other breast lesions. They have very low mitotic index and rarely manifest as a symptomatic lesion, most cases being incidentally detected on imaging $[8,9]$. When symptomatic, the clinical presentation may range from a single firm, mobile, lump to multiple nodules in about two-third of cases [2,3,8-11]. The imaging appearances often simulate other common benign tumors, such as fibroadenoma or phyllodes. Because of considerable overlap of imaging features, the definitive diagnosis is established on histopathology [9].

On mammography, the most common appearance is a high-density, circumscribed, non-calcified mass. Suspicious features such as architectural distortion and spiculated margins are exceptionally rare $[8,9,12]$ . On ultrasound, PASH is usually seen as a well-defined hypoechoic solid mass. Rarely, it may have a heterogeneous appearance with some cystic areas [13]. Our patient had well-circumscribed mass with smooth margins on ultrasound with few cleft-like anechoic cystic areas; however, large size, skin thickening and enlarged axillary lymph nodes were suspicious for malignancy and prompted extensive workup. Mammography was not performed as the patient was lactating.

On MRI, tumorous PASH may appear as a well-defined lesion showing gradual progressive enhancement on post-contrast sequences mimicking fibroadenoma [4]. Non-mass enhancement is rarely reported [13]. Such enhancement may simulate DCIS requiring biopsy to confirm this benign entity, especially in high-risk patients.

The definitive diagnosis is established on biopsy. The histological features of PASH may be confused 
with low-grade angiosarcoma; however, angiosarcoma shows anastomosing spaces filled with red blood cells invading the adjacent breast parenchyma and the absence of collageneous stroma, unlike PASH [6,11]. The hallmark of PASH is dense stromal proliferation with multiple slit-like spaces lined by bland spindle-shaped cells mimicking tiny blood vessels. Also, the proliferating myofibroblasts show positive expression of CD34 immunohistochemical stain in PASH [6]. This feature was also observed in our case.

The treatment of PASH may be either surgical or non-surgical. Surgery is usually reserved for large symptomatic lesions with pain or enlargement $[3,4,14]$. As malignant transformation is extremely rare, serial imaging follow-up for few years can be considered for cases that are small, incidentally discovered or when it is asymptomatic $[4,6,9]$. Given the possible etiological role of hormones, anti-hormonal therapy can also be considered as an alternative non-invasive approach in the management of tumor-forming PASH [14]. Our patient did not opt for surgery. She was prescribed lactation suppression drug as she was lactating along with tamoxifen and pain medication, and the lesion remarkably regressed in size on clinical follow-up. The patient unfortunately did not have any post-treatment imaging.

\section{Conclusions}

PASH is an uncommon histologic finding in breast biopsy specimens, often an incidental discovery. Uncommonly, it may present as a palpable breast mass and be indistinguishable from other benign breast masses. Rarely, it may attain a size or clinical appearance where it may be confused with malignancy. A core needle biopsy confirms the diagnosis. Large symptomatic masses may require excision. Some cases, which are hormone responsive, may benefit from conservative management.

\section{Additional Information \\ Disclosures}

Human subjects: Consent was obtained by all participants in this study. The Aga Khan University issued approval 2020-3560-9081. This study was reviewed and approved as exemption. Conflicts of interest: In compliance with the ICMJE uniform disclosure form, all authors declare the following: Payment/services info: All authors have declared that no financial support was received from any organization for the submitted work. Financial relationships: All authors have declared that they have no financial relationships at present or within the previous three years with any organizations that might have an interest in the submitted work. Other relationships: All authors have declared that there are no other relationships or activities that could appear to have influenced the submitted work.

\section{References}

1. Virk RK, Khan A: Pseudoangiomatous stromal hyperplasia: an overview. Arch Pathol Lab Med. 2010, 134:1070-1074.

2. Vuitch MF, Rosen PP, Erlandson RA: Pseudoangiomatous hyperplasia of mammary stroma. Hum Pathol. 1986, 17:185-191. 10.1016/s0046-8177(86)80292-1

3. Sasaki Y, Kamata S, Saito K, Nishikawa Y, Ogawa J: Pseudoangiomatous stromal hyperplasia (PASH) of the mammary gland: report of a case. Surg Today. 2008, 38:340-343. 10.1007/s00595-007-3613-6

4. Raj SD, Sahani VG, Adrada BE, et al.: Pseudoangiomatous stromal hyperplasia of the breast: multimodality review with pathologic correlation. Curr Probl Diagno Radiol. 2017, 46:130-135. 10.1067/j.cpradiol.2016.01.005

5. Donk WA, Oostenbroek RJ, Storm RK, Westenend PJ, Plaisier PW: Pseudoangiomatous stromal hyperplasia: diagnosis, treatment and follow-up; description of a case-series. Open Breast Cancer J. 2011, 3:18-23.

6. Bowman E, Oprea G, Okoli J, et al.: Pseudoangiomatous stromal hyperplasia (PASH) of the breast: a series of 24 patients. Breast J. 2012, 18:242-247. 10.1111/j.1524-4741.2012.01230.x

7. Anderson C, Ricci A Jr, Pedersen CA, Cartun RW: Immunocytochemical analysis of estrogen and progesterone receptors in benign stromal lesions of the breast. Evidence for hormonal etiology in pseudoangiomatous hyperplasia of mammary stroma. Am J Surg Pathol. 1991, 15:145-149. 10.1097/00000478-199102000-00007

8. Cohen MA, Morris EA, Rosen PP, Dershaw DD, Liberman L, Abramson AF: Pseudoangiomatous stromal hyperplasia: mammographic, sonographic, and clinical patterns. Radiology. 1996, 198:117-120. 10.1148/radiology.198.1.8539361

9. Vo QD, Koch G, Girard JM, et al.: A case report: pseudoangiomatous stromal hyperplasia tumor presenting as a palpable mass. Front Surg. 2016, 2:73. 10.3389/fsurg.2015.00073

10. Ferreira M, Albarracin CT, Resetkova E: Pseudoangiomatous stromal hyperplasia tumor: a clinical, radiologic and pathologic study of 26 cases. Mod Pathol. 2008, 21:201-207. 10.1038/modpathol.3801003

11. Ibrahim RE, Sciotto CG, Weidner N: Pseudoangiomatous hyperplasia of mammary stroma. Some observations regarding its clinicopathologic spectrum. Cancer. 1989, 63:1154-1160. 10.1002/10970142(19890315)63:6<1154::aid-cncr2820630619>3.0.c0;2-q

12. Polger MR, Denison CM, Lester S, Meyer JE: Pseudoangiomatous stromal hyperplasia: mammographic and sonographic appearances. AJR Am J Roentgenol. 1996, 166:349-352. 10.2214/ajr.166.2.8553945

13. Jones KN, Glazebrook KN, Reynolds C: Pseudoangiomatous stromal hyperplasia: imaging findings with pathologic and clinical correlation. AJR Am J Roentgenol. 2010, 195:1036-1042. 10.2214/AJR.09.3284

14. Pruthi S, Reynolds C, Johnson RE, Gisvold JJ: Tamoxifen in the management of pseudoangiomatous stromal hyperplasia. Breast J. 2001, 7:434-439. 10.1046/j.1524-4741.2001.07611.x 